\title{
Impact of Soft-Input on the Cost of Resources and Environment in Economic Growth
}

\author{
Empirical Research Based on Chinese Provincial Panel Data
}

\author{
Chunling Pan, Jie Lü \\ The College of Economics and Management, Shenyang Agricultural University, Shenyang, China \\ Email: panchunling91@163.com, jieluesy@163.com
}

Received May $31^{\text {st }}, 2012$; revised July $28^{\text {th }}, 2012$; accepted August $26^{\text {th }}, 2012$

\begin{abstract}
China's rapid economic growth has proceeded at considerable cost of resources and environment. To find out how to reduce the cost while maintaining economic growth, we took panel data of 28 provinces from 2000 to 2009 as our samples and conducted comparative analysis on the said cost among 28 provinces. From the perspective of soft-input, we subsequently examined soft-input's influence on the cost of resources and environment of in economic growth (CREIEG). Results show that: government spending on scientific research and environmental protections has a significant role in reducing energy consumption and wastewater discharge, but it has limited impact on gas emissions and solid waste emissions reduction. Moreover, financial development also has a positive role in reducing energy consumption. Finally, we propose a number of initiatives to reduce the cost of resources and environment of economic growth based on the analysis results.
\end{abstract}

Keywords: Soft-Input; Economic Growth; Cost of Resources and Environment

\section{Introduction}

China has sustained a rapid economic growth. Her per capita GNI, after exceeding $\$ 1000$ for the first time in 2003, reached $\$ 1500$ in 2004 , and rose to $\$ 1740$ in 2005 as a result of further improvement. Her world ranking rose from No. 138 in 2001 to No. 128 in 2005 (National Bureau of Statistics, 2010). However, China's remarkable economic growth has proceeded at considerable cost of both resources and environment. Compared with developed countries, China has relatively low resource-recovery rate. Likewise, her comprehensive utilization rate is also not high. Many usable and reusable resources have been wasted. China is now the world's largest energy-consuming country, and also a country with the largest $\mathrm{CO}, \mathrm{SO}_{2}, \mathrm{CO}_{2}$ emissions as well as other environmentally hazardous substances. The $\mathrm{CO}_{2}$ emissions in China in 2007 took up $22.3 \%$ of the total global emissions (293 million tons), which for the first time exceed the emissions in the United States (International Energy Agency, 2007). The question how to reduce environmental damage to the minimum while maintaining economic growth has become a focus of governmental as well as academic attention in Economists; however, mostly focus their attention on tangible factors, such as capital, raw materials, and labor. These factors invariably have a material form, which is often known as hardinput. But economic growth is something larger than a combination of physical and chemical processes. Human participation will give rise to factors in non-material form. These elements in non-specific material form are known as soft input among economists. They include system, technology, and so on. Compared with research on hard-inputs, there has been little research on soft input and its effect on the cost of resources and environment in economic growth (CREIEG henceforward)

\footnotetext{
*Corresponding author.
}

because of its unmeasured characteristic. In fact, soft-input has at least the same extent of impact on CREIEG as hard-input does.

In summary, the impact of soft input on CREIEG is an important economic issue in both theory and practice. Taking the fast-growing Chinese economy as a case study we use the provincial panel data from 2000-2009 to examine the difference in CREIEG among the provinces under study, and to analyze the impact of soft-input on CREIEG.

The rest of the paper is organized as follows: Section 2 is research design, including a brief introduction of variables, selection of the regression model, and statistical characteristics of variables. Section 3 presents the empirical results. Section 4 is a section of conclusions and suggestions.

\section{Empirical Specifications}

\section{Variable Definitions}

\section{Dependent Variable}

We mainly investigate CREIEG's dimensions of energy efficiency and pollution emission level.

\section{Energy Efficiency Indicators}

Energy consumption per unit GDP (Represented by enegdp) is the ratio of the total energy consumption (tons of standard coal) to Domestic (regional) GDP (million). Energy consumption per unit industry GDP (Represented by eneind) is the ratio of the total energy consumption (tons of standard coal) to domestic (regional) industrial GDP (million). And power consumption per unit GDP (Represented by eneele) is the ratio of the total electricity consumption $(1000 \mathrm{kWh})$ to domestic (regional) GDP (million). 


\section{Pollution Emission Indicators}

Sewage emissions per unit GDP (Represented by watgdp) is the ratio of Sewage emissions (tons) to Domestic (regional) GDP (million). Gas emissions per unit GDP (Represented by gasgdp) is the ratio of gas emissions (standard cubic meters) to domestic (regional) production GDP (million). And solid waste emissions per unit GDP (Represented by solgdp) is the ratio of solid waste emissions (tons) to domestic (regional) GDP (million).

\section{Explanatory Variables}

Soft-input is the sum of non-material elements in addition to the material elements of the production process in certain economies. As defined in (Li, 1995), soft-input divides itself into the following three categories: comprehensive policy investment, comprehensive science and technology investment, and the workers' enthusiasm investment. Comprehensive policy investments include institutional policy and economic management. Since it is difficult to quantify workers' enthusiasm, this paper mainly examines the impact of comprehensive policy investment and comprehensive science-and-technology investment on the environmental cost. Taking the literatures of (Jiang, Hou, \& Liu, 2004; Chao, 2009; Cheng, 2010) and other studies as references, we mainly choose the following variables shown in Table 1.

\section{Regression Specification}

To test the effect of soft input on CREIEG, we use the following regression specification:

$$
\begin{aligned}
y_{i t}= & a_{0}+a_{1} \text { gov }_{i t}+a_{2} \text { open }_{i t}+a_{3} \text { save }_{i t}+a_{4} \text { edu }_{i t} \\
& +a_{5} \text { sci }_{i t}+a_{6} \text { non }_{i t}+a_{7} \operatorname{env}_{i t}+a_{8} \operatorname{cap}_{i t}+\varepsilon_{i t}
\end{aligned}
$$

In the specific regression analysis, we employ Stata statistical software, using fixed effects methods to estimate the above parameters.

\section{Description of Variables}

All data in this paper came from "China Statistical Yearbook" of Chinese National Bureau of Statistics over the years and "China Compendium of statistics", results of variable descrip- tion are shown in Table 2.

Table 1.

\begin{tabular}{|c|c|}
\hline Variable & Definition \\
\hline gov & $\begin{array}{l}\text { Government spending in addition to education divided by } \\
\text { GDP }\end{array}$ \\
\hline open & Total imports and exports divided by GDP \\
\hline save & $\begin{array}{l}\text { Financial institutions' deposits at the end of year divided } \\
\text { by GDP }\end{array}$ \\
\hline edu & Government spending on education divided by GDP \\
\hline sci & $\begin{array}{l}\text { Government spending on scientific research divided by } \\
\text { GDP }\end{array}$ \\
\hline env & $\begin{array}{l}\text { Government spending on environment protection divided } \\
\text { by GDP }\end{array}$ \\
\hline cap & Amount of share capital per Unit employees \\
\hline
\end{tabular}

Variable description.
Table 2.

Parameters variables' summary statistics from 2000 to 2009.

\begin{tabular}{cccccc}
\hline Variable & Obs & Mean & Std. Dev. & Min & Max \\
\hline enegdp & 150 & 1.53 & 0.77 & 0.61 & 4.14 \\
eneind & 150 & 2.81 & 1.55 & 0.81 & 9.03 \\
eneele & 150 & 1.52 & 0.95 & 0.68 & 5.71 \\
watgdp & 310 & 38.97 & 28.20 & 3.98 & 159.90 \\
gasgdp & 279 & 4.35 & 2.79 & 0.49 & 15.54 \\
solgdp & 310 & 2.45 & 1.93 & 0.21 & 10.89 \\
gov & 310 & 15.91 & 11.59 & 5.52 & 92.69 \\
open & 310 & 33.78 & 44.99 & 3.68 & 184.29 \\
save & 279 & 147.40 & 65.62 & 73.19 & 530.87 \\
edu & 310 & 2.76 & 1.50 & 1.30 & 13.83 \\
sci & 310 & 0.16 & 0.17 & 0.03 & 1.43 \\
nonnat & 93 & 58.05 & 18.31 & 19.81 & 89.16 \\
env & 93 & 0.70 & 0.53 & 0.09 & 2.68 \\
cap & 303 & 1.62 & 1.35 & 0.24 & 10.24 \\
\hline
\end{tabular}

Source: National Bureau of Statistics, "China Statistical Yearbook" (2001-2010), China Statistics Press.

\section{Empirical Results}

\section{Abbreviations and Acronyms Comparative Analysis of the Cost of Resources and Environment}

\section{Provincial and Regional Energy Efficiency Comparison}

As shown in Table 3, energy consumption per unit of GDP in eastern provinces is much lower than in central and western provinces. For instance, energy consumption per unit GDP is very high in Shanxi, Qinghai, Inner Mongolia, and Guizhou. But the energy consumption per unit of industrial GDP and electricity consumption per unit GDP show similar geographical characteristics. Therefore, from the perspective of energy consumption, CREIEG in eastern provinces is significantly lower than in central and western provinces. So, when they attempt to change the mode of extensive economic growth, central and western provinces face much more challenge than their eastern counterparts.

\section{Provincial and Regional Pollution Emission Comparison}

From Figure 1, we can see that pollution levels in central and western provinces are much higher than in eastern provinces. Such western provinces as Guangxi, Shanxi, and Chongqing have a relatively high pollution level. From the perspective of environmental pollution, there is a big gap between central and western provinces on the one hand and eastern provinces on the other in terms of quality of economic growth.

Therefore, economic growths in central and western cities are mainly relying on extensive development model due to their lower level of technology and management. While economic growth is inevitably accompanied by high energy consumption and thus high pollution, conditions in various eastern areas 
Table 3.

Trends of energy efficiency.

\begin{tabular}{|c|c|c|c|c|c|c|}
\hline & \multicolumn{2}{|c|}{ Enegdp } & \multicolumn{2}{|c|}{ Eneind } & \multicolumn{2}{|c|}{ Eneele } \\
\hline & 2005-2007 & 2008-2009 & $2005-2007$ & 2008-2009 & $2005-2007$ & 2008-2009 \\
\hline Heilongjiang & 1.41 & 1.25 & 2.22 & 1.64 & 0.96 & 0.83 \\
\hline Jilin & 1.59 & 1.33 & 2.81 & 1.80 & 1.00 & 0.85 \\
\hline Liaoning & 1.77 & 1.53 & 2.89 & 2.34 & 1.36 & 1.17 \\
\hline Beijing & 0.76 & 0.63 & 1.34 & 0.97 & 0.79 & 0.70 \\
\hline Fujian & 0.91 & 0.83 & 1.38 & 1.17 & 1.15 & 1.07 \\
\hline Guangdong & 0.77 & 0.70 & 1.03 & 0.84 & 1.17 & 1.04 \\
\hline Hainan & 0.91 & 0.86 & 3.17 & 2.61 & 0.96 & 0.95 \\
\hline Hubei & 1.90 & 1.68 & 4.16 & 3.16 & 1.53 & 1.47 \\
\hline Jiangsu & 0.89 & 0.78 & 1.55 & 1.19 & 1.21 & 1.11 \\
\hline Shandong & 1.23 & 1.09 & 2.02 & 1.62 & 1.06 & 0.99 \\
\hline Shanghai & 0.86 & 0.76 & 1.13 & 0.96 & 0.96 & 0.85 \\
\hline Tianjin & 1.07 & 0.89 & 1.33 & 0.98 & 1.03 & 0.85 \\
\hline Zhejiang & 0.86 & 0.76 & 1.41 & 1.15 & 1.24 & 1.19 \\
\hline Gansu & 2.19 & 1.94 & 4.63 & 3.79 & 2.52 & 2.47 \\
\hline Guangxi & 1.19 & 1.08 & 2.89 & 2.29 & 1.26 & 1.27 \\
\hline Guizhou & 3.17 & 2.61 & 5.16 & 4.32 & 2.59 & 2.39 \\
\hline Inner Mongolia & 2.40 & 2.08 & 5.31 & 3.87 & 1.91 & 1.79 \\
\hline Ningxia & 4.06 & 3.57 & 8.61 & 6.82 & 5.41 & 4.90 \\
\hline Qinghai & 3.09 & 2.81 & 3.52 & 3.09 & 3.99 & 3.96 \\
\hline Shaanxi & 1.42 & 1.23 & 2.45 & 1.69 & 1.37 & 1.17 \\
\hline Sichuan & 1.49 & 1.36 & 2.99 & 2.36 & 1.26 & 1.12 \\
\hline Xinjiang & 2.08 & 1.95 & 2.90 & 3.05 & 1.23 & 1.37 \\
\hline Yunnan & 1.69 & 1.53 & 3.37 & 2.79 & 1.66 & 1.62 \\
\hline Chongqing & 1.37 & 1.22 & 2.60 & 1.98 & 1.15 & 0.99 \\
\hline Anhui & 1.17 & 1.05 & 2.88 & 2.22 & 1.10 & 1.10 \\
\hline Henan & 1.34 & 1.19 & 3.75 & 2.89 & 1.28 & 1.24 \\
\hline Hubei & 1.46 & 1.27 & 3.28 & 2.51 & 1.19 & 1.06 \\
\hline Hunan & 1.35 & 1.21 & 2.71 & 1.78 & 1.06 & 0.94 \\
\hline Jiangxi & 1.02 & 0.90 & 2.71 & 1.81 & 0.98 & 0.93 \\
\hline Shanxi & 2.86 & 2.46 & 5.96 & 4.72 & 2.39 & 2.11 \\
\hline
\end{tabular}

Source: National Bureau of Statistics, "China Statistical Yearbook" (2001-2010), China Statistics Press.

have become more mature thanks to the reform and opening-up policy. So, those areas can devote more energy to transferring the economic growth mode, saving energy, and protecting environment, which explains why eastern provinces are taking lead in this regard.

\section{Impact of Soft-Input to the Cost of Resources and Environment}

Effect of Soft-Input on Energy Consumption

The effect of soft-input on energy consumption can be seen

\section{in Table 4.}

From Column 1, we can see that save, edu, sci, env, and cap can significantly reduce energy consumption per unit GDP. But in Column 3, we find no significant impact of industrial edu on energy consumption of per unit industry GDP, and in Column 5, there are no significant effects of env, and edu on power consumption per unit GDP. These results indicate that government spending on scientific research and environmental protection have significant role in the reduction of energy consumption. Financial development, likewise, also has a positive role in reducing energy consumption. 


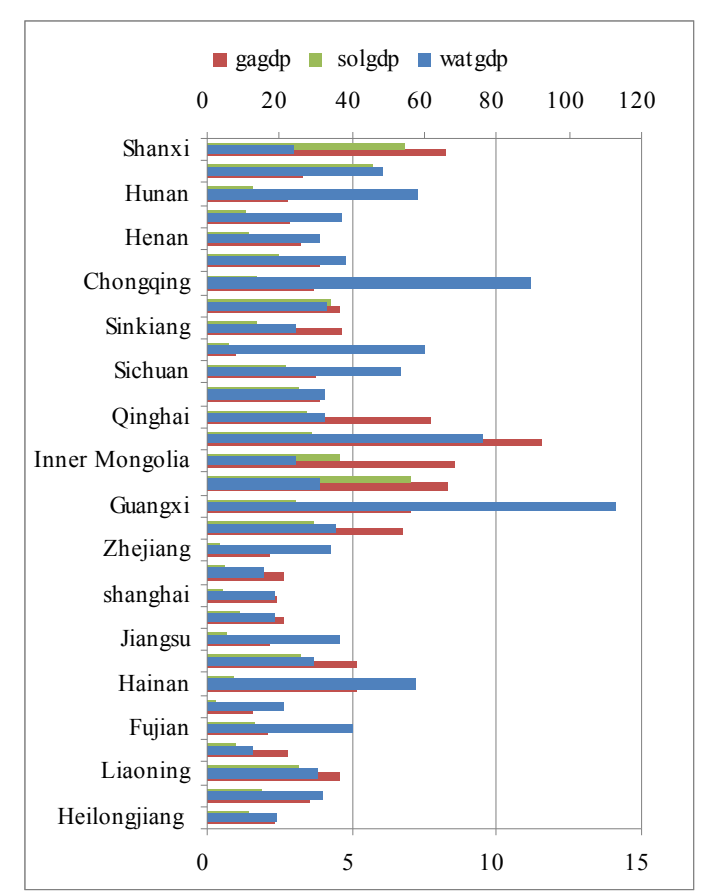

Figure 1.

Provincial average index of industrial pollution from 2000 to 2009. Source: National Bureau of Statistics, "China Statistical Yearbook" (2001-2010), China Statistics Press.

\section{Soft-Input' Effect on Pollution Emission}

Results of soft-input' effect on pollution emission can be seen in Table 5.

From Column 1, we can see that save, sci, non, and env can significantly reduce sewage emissions per unit GDP, but they have no significant effect on gas emissions and solid waste emissions, which can be seen in Columns 3 and 5. This shows that government spending on scientific research and environmental protections has distinct role in the reduction of sewage discharge, but its impact on the reduction of gas emissions and solid waste emissions is rather limited.

The results of empirical analysis have led us to the following conclusions: 1) Compared with eastern cities, central and western cities have higher energy consumption, higher pollution, and hence greater CREIEG; 2) As of the effect of soft-input on CREIEG, governmental soft-input of education investment, scientific-research investment, and environmental investment can significantly reduce the energy consumption per unit GDP, so can the soft-input of financial-development level and share capital per unit employees. Moreover, government expenditures on scientific research and environmental protection can decrease Sewage discharges.

The following measures can be taken to reduce CREIEG: since government is currently the main soft-input body, we should make it possible for more participants, especially companies, to join the soft-input projects. We should continue to deepen the reform of financial system, improve capital allocation efficiency, strengthen cooperation between economically developed regions and less developed regions, apply differential financial institutions and more preferential policies for economically underdeveloped areas. Finally, since educational investment and science-and-technology investment, through the
Table 4.

Effect of soft-input on energy consumption Soft-input' effect on pollution emission.

\begin{tabular}{ccccccc}
\hline & \multicolumn{2}{c}{ Enegdp } & \multicolumn{2}{c}{ Eneind } & \multicolumn{2}{c}{ Eneele } \\
\cline { 2 - 7 } & $\mathbf{( 1 )}$ & $\mathbf{( 2 )}$ & $\mathbf{( 3 )}$ & $\mathbf{( 4 )}$ & $\mathbf{( 5 )}$ & $\mathbf{( 6 )}$ \\
\cline { 2 - 7 } & $\boldsymbol{b}$ & $\boldsymbol{t}$ & $\boldsymbol{b}$ & $\boldsymbol{t}$ & $\boldsymbol{b}$ & $\boldsymbol{t}$ \\
\hline gov & 0.01 & 0.98 & 0.02 & 0.59 & -0.00 & -0.01 \\
open & -0.00 & -0.91 & -0.00 & -0.72 & -0.00 & -0.55 \\
save & $-0.00^{* * *}$ & -3.12 & $-0.01^{* *}$ & -2.15 & $-0.01^{* *}$ & -2.55 \\
edu & $-0.09^{* *}$ & -2.26 & -0.06 & -0.36 & 0.00 & 0.03 \\
sci & $-0.94^{* * *}$ & -2.87 & $-2.30^{*}$ & -1.76 & $-1.78^{* * *}$ & -2.96 \\
non & -0.00 & -0.54 & -0.02 & -1.17 & 0.00 & 0.15 \\
env & $-0.08^{* *}$ & -2.01 & $-0.63^{*}$ & -1.84 & -0.05 & -0.31 \\
cap & $-0.09^{* * *}$ & -3.00 & $-0.30^{* *}$ & -2.30 & $-0.15^{* *}$ & -2.70 \\
Cons & $2.38^{* * *}$ & 12.92 & $5.95^{* * *}$ & 7.48 & $2.20^{* * *}$ & 6.52 \\
Obs & 60 & & 60 & & 60 & \\
$\mathrm{R}^{2}$ & 0.78 & & 0.30 & & 0.66 & \\
\hline Note: ${ }^{* * *}, * *{ }^{*}$ indicate significant at $1 \%, 5 \%$ and $10 \%$ respectively.
\end{tabular}

Table 5.

Effect of soft-input on pollution emission.

\begin{tabular}{ccccccc}
\hline & \multicolumn{2}{c}{ watgdp } & \multicolumn{2}{c}{ gasgdp } & \multicolumn{2}{c}{ solgdp } \\
\cline { 2 - 7 } & $\mathbf{( 1 )}$ & $\mathbf{( 2 )}$ & $\mathbf{( 3 )}$ & $\mathbf{( 4 )}$ & $\mathbf{( 5 )}$ & $\mathbf{( 6 )}$ \\
\cline { 2 - 7 } & $\boldsymbol{B}$ & $\boldsymbol{t}$ & $\boldsymbol{b}$ & $\boldsymbol{t}$ & $\boldsymbol{b}$ & $\boldsymbol{t}$ \\
\hline gov & -0.30 & -0.93 & -0.01 & -0.09 & 0.01 & 0.24 \\
open & 0.04 & 0.54 & -0.01 & -0.17 & -0.01 & -1.11 \\
save & $-0.13^{* *}$ & -2.31 & -0.03 & -1.15 & -0.00 & -0.44 \\
edu & 2.11 & 1.02 & -0.71 & -0.78 & -0.10 & -0.43 \\
sci & $-27.14^{*}$ & -1.73 & 10.04 & 1.44 & 0.63 & 0.36 \\
non & $-0.61^{* * *}$ & -3.32 & -0.06 & -0.75 & -0.00 & -0.07 \\
env & $-4.28^{* *}$ & -2.04 & -2.34 & -1.29 & -0.37 & -0.81 \\
cap & -1.93 & -1.26 & 0.46 & 0.68 & $-0.32^{*}$ & -1.87 \\
Cons & $71.93^{* * *}$ & 7.84 & $11.92^{* * *}$ & 2.94 & $3.83^{* * *}$ & 3.71 \\
Obs & 62 & & 62 & & 62 & \\
$\mathrm{R}^{2}$ & 0.74 & & 0.33 & & 0.35 & \\
\hline
\end{tabular}

Note: ${ }^{* * *},{ }^{* *},{ }^{*}$ indicate significant at $1 \%, 5 \%$ and $10 \%$ respectively.

technological innovations they bring about, play a significant role in decreasing CREIEG, it is extremely important to create an institutional environment that is favorable for technological innovations.

\section{REFERENCES}

National Bureau of Statistics (2010). China statistical yearbook. Beijing: China Statistics Press.

International Energy Agency (2007). Key world energy statistics. URL 


\section{L. PAN, J. LÜ}

(last checked 12 February 2007).

http://www.iea.org/w/bookshop/add.aspx?id=144

Li, G. Z. (1995). Several theoretical issues on soft-input research. Research and Development, 5, 11-14.

Jiang, R. X., Hou, X. L., \& Liu, Y. (2004). Evaluating China's provincial sustainability by integrated indicators. Journal of the Graduate School of the Chinese Academy of Sciences, 21, 63-70.
Chao, X. J. (2009). The quality of economic growth: A theoretical explanation and empirical analysis in China. Ph.D. Thesis, Xi'an: University of Northwest.

Cheng, W. H. (2010). Soft-input and region quality of economic growth. Ph.D. Thesis, Lanzhou: University of Lanzhou. 